\title{
Alturas de Macchu Piccbu: Cantos I-V
}

RESULTA natural que un poeta de obra tan dilatada y de conciencia crítica tan vigilante como Pablo Neruda, se detenga aquí y allá para explicar - para explicarse - su trayectoria lírica e individual, o haga un alto en el camino para preguntarse a dónde ha llegado o qué ruta debe seguir. Esta autoexplicación no se of rece como excrecencia del poetizar, como exégesis que acompaña a la obra desde el margen ${ }^{1}$ : se incrusta en ella, se confunde con su bulto creciente y torrencial, se incorpora al caudal de la producción como hito significativo, con fuerte nexión.

En su poesía temprana ya Neruda se recoge sobre su mismo acto creador y se plantea, por ejemplo, el tema de las resonancias ajenas en sus versos, como ocurre en Crespusculario (1923):

Yo lo comprendo, amigos, yo lo comprendo todo.

Se mezclaron voces ajenas a las mías,

yo lo comprendo, amigos!

Como si yo quisiera volar y a mí llegaran

en ayuda las alas de las aves,

todas las alas,

así vinieron estas palabras extranjeras

a desatar la oscura ebriedad de mi alma.

("Final")

Años más tarde, camino de la madurez definitiva - y tras la experiencia desquiciadora de la Guerra Civil española-, Neruda produce poemas-explicatorios o poemas-sobre-su-poesía, del calibre de "Reunión

1 Al estilo de textos tan conocidos como "Infancia y poesía" o parte de las memorias que publicó Neruda en $O$ Cruzeiro Internacional, entre enero y junio de 1962. Otras veces, la explicación se hace teoría, como en "Sobre una poesía sin pureza", de los tiempos españoles de Caballo verde para la poesía. 
bajo las nuevas banderas" o "Explico algunas cosas". (Y mucho tiempo después, ya en el poema-prólogo del primer libro de sus Odas - "El hombre invisible"-, ya en poemas de los cinco volúmenes del Memo. rial de Isla Negria (1964), esta tendencia natural de la tarea nerudiana seguirá manifestándose como voluntad de hacer de su poesía tema reflexivo desplegado en la misma creación). En tales textos el escritor contempla el rumbo elegido por su lírica y su trayectoria vital (ambas inseparables) y determina - asistido de toda claridad- el futuro que le corresponde tras el despertar de su conciencia social y el descubrimiento de las tareas del poeta en el mundo. Tránsito iluminador que se eleva desde el cantor de idilios, crepúsculos y contemplaciones cósmicas; del observador desgarrado de la perpetua destrucción de lo que nos rodea y hace mundo, al poeta totalmente despierto - ahora sí sin párpados ni descanso-, comparable con una ametralladora capaz de disparar en todas direcciones: ${ }^{2}$ una conciencia vigilante hasta el dolor, cierta misión de la que no hay posible renuncia.

Pero si España en el corazón documenta la ascensión y hallazgo de una poesía cuyo asunto son las tribulaciones y angustias colectivas y la postura del artista ante tales injusticias - todavía en una dirección general humanitaria-, en Alturas de Macchu Piccbu, sobre todo en su segunda sección, nos ofrecerá la neta canalización americana de ese hallazgo lírico y, junto a ella, el encuentro de su más feliz cristalización verbal. Así, con independencia de subidos valores poéticos, Alturas... traduce el hallazgo del derrotero que lleva, sin desvío posible, a las cimas de la expresión americana buscada desde los balbuceos literarios del continente. ${ }^{3}$ ¿No sorprende seguir el cumplimiento que Neruda ha-

2 "A una entrevista que se me hizo en Colombia sobre cuáles eran mis proyectos en poesía, respondí que ellos tomarían la forma de los sucesos de esta época. No soy un poeta - contesté-; en este momento soy una ametralladora y disparo cuando es necesario". Pablo Neruda, en una entrevista que publicó el diario El Siglo, de Santiago, el 5 de diciembre de 1943. Citado por Hernán Loyola, "Los modos de autorreferencia en la obra de Pablo Neruda". Aurora, 2a. época, I [1964], n. 3-4, página 94.

3 La crítica suele indicar que la "conversión" poética de Neruda ocurre en el ámbito de España en el Corazón, como consecuencia de su participación en la Guerra Civil y su testimonio de las desgracias del pueblo en guerra. Véase, por ejemplo, el estudio de Mario Rodríguez, "Reunión bajo las nuevas banderas o de la conversión poética de Pablo Neruda". Mapocbo [Biblioteca Nacional, Santiago de Chile], II [1964], n. 3, pp. 238-248.

Pero, asimismo, téngase presente la atinada observación de Jaime Concha: "La crítica, casi toda, identifica esta transformación con España en el corazón. Esto es verdad. Con la breve corrección de que su plasmación imaginaria definitiva sólo puede situarse en Alturas de Maccbu Piccbu". J. Concha, "El descubrimiento del pueblo en la poesía de Neruda". Aurora [Santiago, Chile], segunda Época, I [1964], n. 3-4, página 127.

Sobre los asuntos "americanos" en la lírica, téngase presente que Gabriela 
ce del "programa" de don Andrés Bello, cuando en el Canto General, su elogio lírico se concentra en héroes (y antihéroes), acciones y pai. sajes?

Lectores y críticos perciben en Alturas de Macchu Piccbu la intención del poeta de ofrecer dos momentos o fases de clara diferenciación, en que un eje deíctico (el entonces ilativo, encabezador del canto sexto) impone un tajo rotundo en el contenido: la historia de una agonia existencial, primero, y después la alabanza, más que la elegía, de la ciudad muerta, de la "madre de piedra". A dicha escisión contribuyen, asimismo, una diferente concepción de la forma poética (falta de coagulación formal / formalización); un distinto temple de ánimo (an. gustiado / esperanzado); una evidente oposición sintáctica (dislocación / voluntad ordenadora) e igualmente dos códigos metafóricos o imaginísticos. ${ }^{4}$ En términos gruesos, ditíamos que la muerte cotidiana, la asfixia de la vida vacía, la inautenticidad son reveladas en la primera parte del poema; el hacer en la hermandad, en lo solidario, en la segunda, a través de la contundente ejemplaridad de la ciudad enclavada en la "atroz maraña".

Lo anterior nos conduce a aceptar lo que la exégesis nerudiana, y el propio autor, han puesto en claro: Alturas de Macchu Picchu, como poema, es portador de un pormenorizado balance de la vida-creación de Neruda, quien llega a ese momento revelador en un instante crítico, en consonancia con agudas convulsiones de época y significativas decisiones de su destino político personal: a la Guerra Civil española, a la invasión italiana de Etiopía, ha sucedido la Segunda Guerra Mundial. La conciencia del poeta -agudizando hasta la agonía lo que perciben sus contemporáneos- descubre por segunda vez en menos de un cuarto de siglo lo que puede aguardarse de la rectora Europa, la que impusiera, hasta hace muy poco, las direcciones fundamentales en el arte y la cultura iberoamericanos. Es un momento propicio para reafirmar de modo definitivo todo el alcance y la esperanza cierta en el Nuevo Mundo como 'altura', como zona de ala y vuelo, como cima y cifra.

En tal momento - confluencia de encrucijada personal y colectiva-

Mistral, en una de las notas a Tala [1938], la que lleva por título "Dos himnos", estableció lo que esperaba al poeta fatigado de joyerías y suntuosidades de la tradición modernista: "Suele echarse de menos, cuando se mira a los monumentos indigenas o a la Cordillera, una voz entera que tenga el valor de allegarse a esos materiales formidables". Véase, en las llamadas Poesías completas de G. Mistral, Madrid: Aguilar, 1962, 2a. edición, la página 805.

4 Véase el detallado estudio de Gastón Carrillo H. "Ia lengua poética de Pablo Neruda: Análisis de Alturas de Maccbu Picchu". Boletin de Filologia, Universidad de Chile, XXI [1970], pp. 293-332. 
y dos años después de su visita a las ruinas o "alturas", escribe Neruda el poema: 1945.

He aqui, en la autorizada opinión del crítico chileno Hernán Loyola, lo que significa Alturas de Macchu Piccbu como poema-síntesis:

La significación del poema radica en el hecho de reflejar el punto culminante de una encrucijada dialéctica, la resolución final de una etapa del proceso interior que venía viviendo Neruda $y$, al mismo tiempo, la apertura de una nueva etapa. Balance y rumbo nuevo. A través de una condensación lírica, admirablemente concebida y realizada, Neruda registra el momento en que se hace un alto en el camino de su conciencia, el instante en que se sumerge hasta el fondo de sí mismo para tomar un poderoso impul. so hacia adelante. Porque no es casual que Alturas de Macchu Picchu implique, inclusive en la disposición de sus partes, una suma sintética de revisiones hacia el pasado y de propósitos hacia el futuro, un examen de todos los aspectos que conformaban su situación vital en ese tiempo... ${ }^{5}$

Nos interesa por ahora sondear, en las cinco estrofas iniciales del poema, la revisión que Neruda cumple de su pasado poético confundido con su vivir; acentuar la consonancia entre la 'historia' de quien las escribió y la postura de la época - muy marcada por los principios generales del existencialismo-, que la novela de esos años y de los venideros revelará de modo parecido. Nos permite lo último sostener que tan cierto es que la lírica de 1920-1930 (Vallejo, Huidobro, Neru$\mathrm{da}$, entre otros) preludia la audacia y el irrespeto verbales de la "nueva novela", como que algunas de sus más destacadas condensaciones temáticas ya aparecen en aquella función literaria. Muchos de los problemas espirituales del narrador-protagonista-innominado de Los pasos perdidos, por ejemplo, están preludiados por el yo lírico de las Residencias... y su consecuente re-presentación en las primeras cinco unidades de las Aluras: fatiga ante la rutina, noción de vaciedad e incomunicación, carencia de toda tensión vital, inautenticidad, existir angustiado, mineralización de un vivir casi objetal, degradante, sin urgencias ni compromisos que rediman.

El lector de las estrofas iniciales de Alturas de Maccbu Piccbu se

5 Hernán Loyola, "Los modos de autorreferencia en la obra de Pablo Neruda". Aure ra, segunda época, I [1964], n. 3-4, página 95. Igualmente, en el libro del mismo critico, Ser y morir en Pablo Neruda. Santiago: Editora Santiago, 1967. Páginas 197-198. 
enfrenta con un temple de ánimo que es todavía residual o rememorativo del sombrío y desesperanzado de las Residencias, sobre todo el de los volúmenes uno y dos; es decir, poemas cuya cronología es 1927-1931 y 1931-1935. Así, la "autobiografía" que quiso formular Neruda en esta sección del poema se enmascara con los rostros "salobres" del pa. sado. El temple de ánimo dicho, superado en la poesía posterior a la "conversión" del autor, es invocado y atraído nuevamente a la contemplación del lector como culpa y para que sea contrastado con la operación rectificadora y el impacto de Macchu Picchu como piedra-base de la solidaridad del hombre, de su voluntad constructora.

El código metafórico y verbal imperante en la sección inicial del poema - como la condición espesa de su sintaxis- tiene mucho que ver con el emitido por el yo lírico de las Residencids, fatigado por la urbe, socialmente decepcionado, ${ }^{6}$ víctima del agobio de establecimientos, rutinas y símbolos de la "inexistencia", del vivir cortical: red vacia, al. fombra cotidiana, máscaras precipitadas, movimientos metalicos, acontecimientos miserables, muerte pequeña, copa negra, corta muerte diaria, etc. $\mathrm{El}$ hombre que se desplaza en la ciudad aplastante, es representado en los términos de su caída y agobio espirituales como "el roedor de las calles espesas".

Del aire al aire, como una red

vacía,

iba yo entre las calles y la atmósfera, llegando y despidiendo,

en el advenimiento del otoño la moneda extendida

de las hojas...

El hablante poético con vigor inicia su autorrepresentación en el pasado culpable -ontológicamente: por inautenticidad- con la intensa comparación de la "red vacia" (doble vacío) que oscila, sin asir, en el aire o los espacios populosos. La concreción imaginativa red tra. duce en grado óptimo y ajustado el inútil esfuerzo por aprehender sentido. El yo se desnuda como sólo testigo y contemplador de los cambios que trae el repetido giro y la mecánica de las estaciones: veedor

- Jaime Concha, en su esclarecedor ensayo "Interpretación de Residencia en la Tierra de Pablo Neruda", Mapocbo [Biblioteca Nacional, Santiago de Chile], I [1963], n. 2, pp. 5-39, ha tratado la "decepción de la sociedad" y la condición "pesimista" de metafísica de las Residencias como resultante de "una experiencia negativa del ser humano". 
del Tiempo, jamás su dueño. ${ }^{7} \mathrm{La}$ comparación dominante denuncia un mero resbalar por la superficie del mundo, un ser inerte, ni comprometido ni riesgoso que -a veces- logró instantes de profundidad en la relación amorosa reveladora y auténtica, aunque fugaz: algunos 'momentos perfectos' y plenos ("días de fulgor vivo"), en la conversación de los cuerpos desnudos (el mundo lírico de Crepusculario y Veinte poemas de amor...): la máxima tensión erótica de los

(Días de fulgor vivo en la intemperie

de los cuerpos: aceros convertidos

al silencio del ácido:

noches deshilachadas hasta la última harina:

estambres agredidos de la patria nupcial).

Pero hasta el amor que se prometía más duradero e indestructible, sucumbe a la ley que gobierna las cosas y las encamina a su secreto desgaste o destrucción: los luchadores son

aceros convertidos

al silencio del ácido...

Tras ellos, el ensimismamiento, las tareas de profundidad del pálido buzo ciego: "alguien" que le aguardaba en el bosque de las maderas (materias) esenciales, en la armonía profunda de la intimidad terrestre ("entre los violines"), le mostró la dirección geológica, el secreto de lo mineral como fuente posible de que henchir la red-vida. El descenso no aporta revelaciones y "desde lo más genital de lo terrestre" tetorna el hablante sin iluminaciones ("como un ciego") al orden social de las máscaras y las repeticiones degradantes:

Puse la frente entre las olas profundas, descendí como gota entre la paz sulfúrica, $y$, como un ciego, regresé al jazmín de la gastada primavera humana.

7 Véase este mismo asunto tratado en el plano narrativo y con evidente sello existencialista en Los pasos perdidos de Alejo Carpentier. La comunidad genera. cional -Neruda y Carpentier nacen en 1904-y la respuesta, desde la lírica y la narración, a similares inquietudes y congojas de la época son contundentes 
Víctima de cuidados pequeños, el hablante del poema se autorre. presenta - por contraste con la flor y la toca y lo solidario vegetal. mineral - como isla, agobiado por direcciones inauténticas e incomunicación, estrangulado por el nudo buroctático, entre rutinas embrutecedoras y frías: si el vegetal se comunica y vincula, el hombre, en cambio, se ensimisma y encierra, se defiende con muros, puertas y silencio, se niega al nexo y se mutila en espíritu. El esquema de contraste es evidente:
Si la flor a la flor entrega
el alto germen...
el hombre arruga el pétalo de la luz...

El alma, agredida por lo externo insignificante (la ropa) y por la fatiga de la ciudad que asfixia (el humo), queda expuesta a la frialdad de la existencia sin destino ni relieves, significada aquí en lo gélido:

Y pronto, entre la ropa y el humo, sobre la mesa hundida como una barajada cantidad, queda el alma:

cuarzo y desvelo, lágtimas en el océano como estanques de frío...

Jugamos con el alma con el mismo descuido con que el tahur avezado arroja sobre el tablero unos naipes manoseados (barajada cantidad), opuestos a su alto destino en la realización de la existencia. Así, la decepción del espacio anulador y rutinario, propia del despliegue imaginario de las Residencias (oficinas, almacenes, notarios, establecimientos, peluquerías y cines) vuelve con inusitado vigor al poema. Compárese el fragmento que sigue, de "Desespediente" (donde ya se convocan los papeles que hacen agonizar al alma) con la secuencia observada:

La paloma está llena de papeles caídos, su pecho está manchado por gomas y semanas, por secantes más blancos que un cadáver y tintas asustadas de su color siniestro. Ven conmigo a la sombra de las administraciones, al débil, delicado color pálido de los jefes, a los túneles profundos como calendarios, a la doliente rueda de mil páginas...

$$
\text { ("Desespediente", Residencia..., II). }
$$


pero aún

mátala y agonízala [el alma] con papel y con odio, sumérgela en la alfombra cotidiana, desgárrala entre las vestiduras hostiles del alambre...

\section{(Alturas...).}

Ciertos símbolos, como alfombra, por su asociación con pisadas ( $\mathrm{y}$ su alcance hasta bumillación) conducen a prolongar la energía mandatoria de matala / agonizala = pisotéala / bumillala (al alma), hazla probar todos los peldaños de la degradación, así como "desgárrala entre las vestiduras hostiles del alambre" empuja nuestra imaginación a enjáulala, 'condénala al cautiverio más feroz y doloroso'.

El hablante del poema reitera el contraste entre los trabajos de la naturaleza, cuyo "rocío desde mil años deja su carta transparente" ... "en la altura del ciruelo", y su propia falta de éxito cuando quiso formular interrogaciones ontológicas y pugnó por el hallazgo del Fundamento $\mathrm{y}$ sus revelaciones: "la eterna veta insondable", percibida ya en la autenticidad primaria de la piedra o en el momento de la comunión amorosa ("en la piedra o en el relámpago que el beso desprendía"), no se daba desde el hombre mismo, que se recogía y negaba. No halló el hablante lírico sino la soledad entre muchos a-islados, ya en la ciudad, en un autobús, en un barco o en la opresora soledad de las fiestas ( $e l$ estar "triste de fiestas" dariano!) o en la misma búsqueda de unión en el acoplamiento sexual:

Cuántas veces en las calles de invierno de una ciudad o en un autobús o un barco en el crepúsculo, o en la soledad más espesa, la de la noche de fiesta, bajo el sonido de sombras y campanas, en la misma gruta del placer humano, me quise detener a buscar la eterna veta insondable que antes toqué en la piedra o en el relámpago que el beso

[desprendía...

8 Sobre la búsqueda del Fundamento en Neruda, véase el estudio de Jaime Concha, mencionado en la nota 6.

- Ciudad, autobús, barco, fiesta, para traducir, sin duda, la reunión por ciego azar, que no asegura, con la cercanía o el apretujamiento comunicación o comu. nión. Recuérdese, por ejemplo, la metáfora del barco-viaje en Los premios de Julio Cortázar; o la momentánea 'unión' en una carretera atascada, en "La autopista del Sur", del mismo escritor. 
La estrofa parentética que sigue señala cómo esa "veta insondable" se anuncia en el trigo y el agua que, en oposición al lobo-hombre, saben darse: que son, grano y grano, como un número que no concluye, u onda y onda transparente, de cordillera a mar, en indestructible vínculo:

(Lo que en el cereal como una historia amarilla de pequeños pechos preñados va repitiendo un número que sin cesar es ternura en las capas germinales, y que, idéntica siempre, se desgrana en marfil y lo que en el agua es patria transparente, campana desde la nieve aislada hasta las olas sangrientas)

Mortificación del hablante es que la solidaridad del mundo vegetal o mineral no se repita entre los hombres: que éstos sean una larga cadena de máscaras, cuya respuesta hierática conduce a la interrogación ontológica por excelencia: ¿dónde residen el vivir auténtico, la existencia plena?

No pude asir sino un racimo de rostros o de máscaras precipitadas, como anillos de oro vacío, como ropas dispersas hijas de un otoño rabioso que hiciera temblar el miserable árbol de las razas asustadas.

No tuve sitio donde descansar la mano

y que, corriente como agua de manantial encadenado, o firme como grumo de antracita o cristal, hubiera devuelto el calor o el frío de mi mano extendida...

Entre lo frío y lo agresivo, ¿qué era y dónde estaba el hombre? O bien, ¿dónde se disimulaba, hasta perderse, "lo imperecedero" si la criatura estaba condenada a rutinas ominosas ("los almacenes", que son las 'oficinas' y los 'establecimientos' del mundo de las Residencias), a agresiones del bullicio ciudadano ("los silbidos", lo sonoro que desquicia y no lo sonoro de la vida plena) y a una conducta de robot ("sus movimientos metálicos") ? La respuesta a ese brutal interrogante -máximo abrazo de la poesía y el filosofar- será que el hombre, ocupado en su morir rutinario de cada día, deslustrado por la costumbre, permite que se apague su conciencia y su más angustiosa certeza: la de constituir, en términos heideggerianos, un Sein zum Tode. La tespuesta a la enorme pregunta: 
¿Qué era el hombre? ¿En qué parte de su conversación abierta entre los almacenes y los silbidos, en cuál de sus movimientos

vivía lo indestructible, lo imperecedero, la vida?,

[metálicos

es el objeto del canto III de Alturas...

\section{III}

La distracción del ser en pequeñas agonías de la vida cotidiana -odios, deudas, temores, miserias diminutas- constituye una diaria muerte insignificante que oculta u opaca la noción de la gran muerte, la muerte personal o propia, esa que - paradojalmente- tenemos que 'vivir' como término, como resolución final. Esos son los hombres que sorprendió el hablante del poema: de esas vidas fue testigo.

Olvidados de que constituimos criaturas-para-la-muerte, de que la llevamos en el bolsillo o en los trajes (como en algún poema de ViIlaurrutia), tendemos a resbalar sobre el mundo, a sobre-vivirlo, sin compromiso, negándonos al riesgo y la intensidad. Tales mutilaciones cotidianas se visualizan en la comparación concreta con el maíz que va perdiendo sus granos, su real corporeidad:

El ser como el maíz se desgranaba en el inacabable granero de los hechos perdidos, de los acontecimientos miserables, del uno al siete, al ocho, y no una muerte, sino muchas muertes llegaba a cada uno: cada día una muerte pequeña...

La crítica nerudiana nos aclara que aquí el poeta entronca con la tradición literaria de los poetas meditativos, como Rainer M. Rilke: "La cuestión de la muerte en los cinco primeros cantos de Alturas de Maccbu Piccbu está propuesta en el modo más propio de los grandes poetas metafísicos", escribe Mario Rodriguez F. ${ }^{10}$

3.0 Mario Rodríguez F., "El tema de la muerte en Alturas de Maccbu Picchu de Pablo Neruda". Anales de la Universidad de Chile, CXXII [1964], n. 131, página 24.

El trato de Neruda con textos de Rilke ya estaba establecido en 1926. En el número 135 de la revista Claridad, octubre-noviembre de este año, Neruda tradujo del francés un fragmento de los Cuadernos de Malte Laurids Brigge (versión de Gide). Al verter el texto al español, Neruda escribió en un pasaje: "Antaño se sabía [...] que cada uno contenía su propia muerte como el fruto su hueso..." Citado por Hernán Loyola, Ser y morir en Pablo Neruda, obra ya mencionada, paginas $70-71$. 
Para los cuitados -aquéllos que, como en Residencia..., reconocen en el día el espacio de la desesperación - no queda sino el desgaste en mínimas muertes, en hechos deleznables que la víctima traga como el contenido de una copa abyecta bebida entre temblores: se trata de una muerte sufrida antes de llegar a la Muerte:

Todos fallecieron esperando su muerte, su corta muerte diaria:

y su quebranto aciago de cada día era como una copa negra que bebían temblando.

\section{IV}

La cuarta unidad de esta "serie de recuerdos autobiográficos" (es decir, revisiones de estado de su poética en el pretérito y, sobre todo, del de la etapa "residenciaria") opone a la pequeña muerte cotidiana y sin relieves, la desoladora visita, reto o cita de la Muerte. El yo lírico evoca su tiempo más asolado por la visita de lo luctuoso y la conciencia de un perpetuo deshacerse: el ámbito de las Residencias con su sistema verbal e imaginario propio, con su catálogo de catástrofes: sales aniquilantes, ácidos, derrumbes, humedad corrosiva, espacios adversos y agresivos, cercanía de lo feo, todo enmarcado por lo funesto y lúgubre, sin tregua.

Una y otra vez el poeta sucumbió a los llamados de la muerte y diseminó a través de sus versos esa aterradora presencia, dotada de la argucia destructora de la sal en las olas: dueña de pasos secretos:

La poderosa muerte me invitó muchas veces:

era como la sal invisible en las olas,

y lo que su invisible sabor diseminaba

era como mitades de hundimientos y altura

o vastas construcciones de viento y ventisquero...

A la convocatoria se acercó el hablante vertiginosamente atraído y conoció los atributos del horror; tocó casi los filos de la guadaña (la elaboración imaginaria de la tradición no nos despista tanto como para no reconocer la antropomorfización de la señora de la cuchilla curva). O bien, testigo ("Yo veo muertos..."), espió a las víctimas, para reconocer en ella el cuerpo mismo de la muerte "cortando el hilo". Estuvo junto a los agónicos que pugnan por limosnas de aire, junto a las mortajas y las putrefacciones, al borde de los solemnes silencios y en el 
momento en que la vida huye por una loca carretera espiral, remontándose: pero no halló el rostro de la muerte, porque ésta es inabarcable e inasible ("ancho mar"), a pesar de sus tareas concretas, e invade co. mo la luz o la tiniebla, poderosamente diseminada:

Yo al férreo filo vine, a la angostura

del aire, a la mortaja de agricultura y piedra,

al estelar vacío de los pasos finales

y a la vertiginosa carretera espiral:

pero, ancho mar, oh muerte!, de ola en ola no vienes,

sino como un galope de claridad nocturna

o como los totales números de la noche. . ${ }^{11}$

La Muerte pisa con firmeza, deja huella concreta (en "Sólo la muerte" la vemos poniendo huevos), mas no se la puede sorprender como a un ladrón que nos hurga los bolsillos, "con las manos en la masa": su vuelo es veloz y cuando creemos aprehenderla no persisten sino los correlatos externos del morir: oficios religiosos celebrados por sacerdotes de paramentos vistosos; catafalcos navegando por los densos alfombra. dos de los velatorios y su secuela de lágrimas, silenciosa o sonoramente lloradas. ¿Pero dónde está la Muerte?:

Nunca llegaste a hurgar en el bolsillo, no era posible tu visita sin vestimenta roja:

sin auroral alfombra de cercado silencio: sin altos o enterrados patrimonios de lágrimas...

Es evidente el esfuerzo del hablante lírico para apartarse de "falsas muertes" y desplazarse hacia las existencias vividas con riesgo y plenitud, auténticas por saberse para-la-muerte ("más anchas vidas", "más sueltas desembocaduras" - persiste la asociación mantiqueña río-vida, como en "Sólo la muerte"), pero los inexistentes lo rechazan, no quieren despertar a la evidencia de la Poderosa Muerte, entornan puertas. El

1x En este punto, nuestra interpretación difiere mucho de la que ofrece el profesor Félix Schwartzmann en el capítulo "El mundo poético de Pablo Neruda como voluntad de vinculo", de su libro El sentimiento de lo bumano en Amrica, Santiago: Editorial Universitaria, 1953. Tomo II, páginas 63-80. Nos parece más justo interpretar "yo al férreo filo vine. ." como respuesta a la cita solicitada por la muerte, no contaminada aún con la experiencia de Macchu Picchu. En suma, que el hablante se acercó lo más que pudo a la muerte, para percibir sus atributos y sus operaciones finales en el ser, mas sin éxito. No está, todavía, enfrentado con las "alturas"; ese momento vendrá claramente anunciado por el entonces encabezador del sexto canto. 
hablante, por fin, rueda muriendo de su propia muerte: queda despierto ante una situación que se despliega como límite revelador; como vida consciente en plenitud de la amenaza-promesa de su muerte personal, cabo de toda su realización como ser:

poco a poco el hombre fue negándome

y fue cerrando paso y puerta para que no tocaran

mis manos manantiales ['despertadoras'] su inexistencia herida, entonces fui por calle y calle y tío y río, y ciudad y ciudad y cama y cama, y atravesó el desierto mi máscara salobre, y en las últimas casas humilladas, sin lámpara, sin fuego, sin pan, sin piedra, sin silencio, solo, rodé muriendo de mi propia muerte.

\section{$\mathrm{V}$}

Ahora es posible un tuteo con la muerte ya entrevista: el yo lírico puede asegurarle a ésta, a la Poderosa Muerte, que no tiene nada que ver con la pequeña y diariamente sufrida, con la que se escondía bajo la piel vaciada de seres sometidos a cotidianos dolores menguados:

No eres tú, muerte grave, ave de plumas férreas, la que el pobre heredero de las habitaciones

llevaba entre alimentos apresurados, bajo la piel vacía...

El final del canto $\mathrm{V}$ vuelve a mostrar la futilidad de las búsquedas pasadas. La muerte no se ha entregado: el hablante hurga y hurga, descubre lo que tapan vendas y disfraces, hunde los dedos en los dolores que hacen olvidar a la muerte propia y no extrae sino una "racha fría" (que no es mucho lograr tras tanta andanza) e invasora de los espacios del alma, concebida como 'habitación':

Yo levanté las vendas del yodo, hundí las manos en los pobres dolores que mataban la muerte, y no encontré en la herida sino una racha fría que entraba por los vagos intersticios del alma...

En ese momento de su trance poético-personal - planteo de un fracaso, de un no hallazgo- el hablante del poema que, desde el inicio 
de su "historia" ha ido subiendo hacia la revelación -el sentido multívoco de alturas y el desdén por ruinas se hace claro-, puede proferir el entonces que sepulta lo pretérito y escinde la existencia en búsqueda a tientas / encuentro revelador:

Entonces en la escala de la tierra he subido entre la atroz maraña de las selvas perdidas hasta ti, Macchu Picchu. . .

Por ello, el escritor procede a $l_{a}$ otra fundación de Macchu Picchu, esta vez con la palabra, en el sentido hölderliniano de que permanece y dura lo que establecen los poetas con su verbo: ${ }^{12}$ Llega a tal punto el creador cuando él mismo logra establecerse del modo más auténtico en el mundo: desvelado ante los dolores del hombre, despierto para recordarles su necesidad de vínculo.

Así, Alturas de Macchu Picchu, en sus cinco cantos iniciales, es "autobiografía" en cuanto historia de una búsqueda: la de un asidero final y definitivo. La vida como "inexistencia" le cerró al hablante del poema el acceso a la muerte verdadera y a las subidas tensiones de la autenticidad. La muerte de los otros, la de los hombres de Macchu Picchu, le posibilita la comprensión de la vida como nexo, como aproximación y hermandad indestructible: lo que pudo ser mera elegía -n la mejor tradición funeral de la lengua española - se transformará en cantata de descubrimiento.

University of Micbigan

JUAN LOVELUCK

12 Sobre este verso de Hölderlin ["Pero aquello que permanece es establecido por los poetas"], véase el comentario que formula Martin Heidegger en su ensayo "Hölderlin and the Essence of Poetry". Existence and Being. Chicago: Henry Regnery Co., 1949. Página 304 y ss. 